\title{
The Role of Endoscopy in Small Bowel Neuroendocrine Tumors
}

\author{
Ji Yoon Yoon, Nikhil A. Kumta and Michelle Kang Kim \\ Division of Gastroenterology, Icahn School of Medicine at Mount Sinai, New York, NY, USA
}

Small bowel neuroendocrine tumors (NETs) represent approximately one-third of NETs of the gastrointestinal tract, and their incidence is increasing. When determining if endoscopic resection is appropriate, endoscopic ultrasound is used to assess the lesion size and depth of invasion for duodenal NETs. A number of techniques, including endoscopic mucosal resection (EMR), bandassisted EMR (band-EMR), endoscopic submucosal dissection (ESD), and over-the-scope clip-assisted endoscopic full-thickness resection (EFTR), have been studied; however, the best technique for endoscopic resection remains unclear. The vast majority of currently available data are retrospective, and prospective studies with longer follow-up times are required. For jejunal and ileal NETs, endoscopic techniques such as video capsule endoscopy (VCE) and balloon enteroscopy (BE) assist in diagnosis. This includes localization of the primary NET in metastatic disease where initial workup has been negative, and the identification of multifocal disease, which may change management and prognostication. Clin Endosc 2021;54:818-824

Key Words: Carcinoid tumors; Endoscopy; Neuroendocrine tumors; Small intestine

\section{INTRODUCTION}

Neuroendocrine tumors (NETs) of the gastroenteropancreatic system are a heterogeneous group of neoplasms, with behavior that differs with primary site, histology, and stage. ${ }^{1,2}$ Analysis of population-based registries such as the Surveillance, Epidemiology, and End Results (SEER) Program, have demonstrated increasing incidence of NETs, such that as of the year 2000, NETs were the most common small bowel malignancy, overtaking adenocarcinoma. ${ }^{3}$ Small bowel NETs (SBNETs) comprise approximately $30 \%$ of NETs of the gastrointestinal (GI) tract. ${ }^{4}$ In addition to their rising incidence, SBNETs are likely to be even more common than is captured by

\footnotetext{
Received: November 6, 2020 Revised: December 30, 2020

Accepted: December 30, 2020

Correspondence: Ji Yoon Yoon

Division of Gastroenterology, Icahn School of Medicine at Mount Sinai, One Gustave L Levy Place, New York, NY 10029, USA

Tel: +1-216-293-1249, Fax: +1-212-023-0677, E-mail: Jiyoon.yoon@mountsinai. org

ORCID: https://orcid.org/0000-0002-8897-7144

It is the invited review article.

cc This is an Open Access article distributed under the terms of the Creative Commons Attribution Non-Commercial License (http://creativecommons.org/ licenses/by-nc/3.0) which permits unrestricted non-commercial use, distribution, and reproduction in any medium, provided the original work is properly cited.
}

the SEER registry, which may exclude smaller, more localized NETs that are often considered benign. ${ }^{5}$

Patients are frequently asymptomatic and diagnosed incidentally on cross-sectional imaging or endoscopy for other indications. The clinical presentation of SB-NETs is often insidious and non-specific, with symptoms such as abdominal discomfort and diarrhea present years before diagnosis. The typical carcinoid syndrome is uncommon even in SB-NETs, with $26 \%$ of patients presenting with diarrhea, $13 \%$ with flushing, and $2 \%$ with bronchial constriction. ${ }^{6} \mathrm{Up}$ to a quarter of patients may present with intestinal obstruction. ${ }^{6}$

SB-NETs are classified into stages according to the American Joint Committee on Cancer (AJCC) TNM staging system (Table 1), and grades according to the European Neuroendocrine Tumor Society/ World Health Organization grading system (Table 2), for prognostication.

The evaluation of NETs often includes a combination of biochemical, imaging, and endoscopic modalities. Biochemical markers may include gastrin (duodenal NETs), 5-hydroxyindoleacetic acid (for jejunal/ileal NETs), and chromogranin A, while imaging may include computed tomography (CT), magnetic resonance imaging (MRI), and radiolabeled scintigraphy such as ${ }^{68} \mathrm{Ga}$-DOTATATE PET/CT. On endoscopy, SB-NETs generally appear as round, sometimes subtle subepithelial lesions. ${ }^{7}$ Endoscopic techniques such as video capsule endos- 
Table 1. TNM Staging of Neuroendocrine Tumor of the Small Bowel

\begin{tabular}{|c|c|c|}
\hline & Duodenum (excluding ampulla of Vater) & Jejunum and Ileum \\
\hline \multicolumn{3}{|c|}{ Primary Tumor $(\mathrm{T})$} \\
\hline $\mathrm{TX}$ & Primary tumor cannot be assessed & Primary tumor cannot be assessed \\
\hline T0 & N/A & No evidence of primary tumor \\
\hline $\mathrm{T} 1$ & Invades the mucosa or submucosa only and is $\leq 1 \mathrm{~cm}$ & Invades lamina propria or submucosa and is $\leq 1 \mathrm{~cm}$ \\
\hline $\mathrm{T} 2$ & Invades the muscularis propria or is $>1 \mathrm{~cm}$ & Invades muscularis propria or is $>1 \mathrm{~cm}$ \\
\hline $\mathrm{T} 3$ & Invades the pancreas or peripancreatic adipose tissue & $\begin{array}{l}\text { Invades through the muscularis propria into subserosal tissue } \\
\text { without penetration of overlying serosa }\end{array}$ \\
\hline \multirow[t]{2}{*}{$\mathrm{T} 4$} & Invades the visceral peritoneum (serosa) or other organs & $\begin{array}{l}\text { Invades visceral peritoneum (serosa) or other organs or adja- } \\
\text { cent structures }\end{array}$ \\
\hline & \multicolumn{2}{|c|}{$\begin{array}{l}\text { If number of tumors is known, use T(\#); e.g. pT3(4)NOMO } \\
\text { If the number of tumors is unavailable or too numerous, use the suffix } m-T(m)-\text { e.g.pT3(m)NOMO }\end{array}$} \\
\hline \multicolumn{3}{|c|}{ Regional Lymph Node $(\mathrm{N})$} \\
\hline $\mathrm{NX}$ & Regional lymph nodes cannot be assessed & Regional lymph nodes cannot be assessed \\
\hline No & No regional lymph node involvement & No regional lymph node involvement \\
\hline N1 & Regional lymph node involvement & Regional lymph node metastasis less than 12 nodes \\
\hline $\mathrm{N} 2$ & N/A & $\begin{array}{l}\text { Large mesenteric masses }(>2 \mathrm{~cm}) \text { and/ or extensive nodal de- } \\
\text { posits ( } 12 \text { or greater), especially those that encase the superior } \\
\text { mesenteric vessels }\end{array}$ \\
\hline \multicolumn{3}{|c|}{ Distant Metastasis (M) } \\
\hline M0 & No distant metastasis & No distant metastasis \\
\hline $\begin{array}{l}\text { M1 } \\
\text { M1a } \\
\text { M1b } \\
\text { M1c }\end{array}$ & $\begin{array}{l}\text { Distant metastasis } \\
\text { Confined to liver } \\
\text { In at least one extrahepatic site } \\
\text { Both hepatic and extrahepatic metastases }\end{array}$ & $\begin{array}{l}\text { Distant metastasis } \\
\text { Confined to liver } \\
\text { In at least one extrahepatic site } \\
\text { Both hepatic and extrahepatic metastases }\end{array}$ \\
\hline \multicolumn{3}{|c|}{ AJCC Prognostic Stage Groups } \\
\hline Stage I & T1, N0, M0 & T1, N0, M0 \\
\hline Stage II & $\begin{array}{l}\text { T2, N0, M0 } \\
\text { T3, N0, M0 }\end{array}$ & $\begin{array}{l}\text { T2, N0, M0 } \\
\text { T3, N0, M0 }\end{array}$ \\
\hline Stage III & $\begin{array}{l}\text { T4, N0, M0 } \\
\text { Any T, N1, M0 }\end{array}$ & $\begin{array}{l}\text { Any T, N1/N2, M0 } \\
\text { T4, N0, M0 }\end{array}$ \\
\hline Stage IV & Any $\mathrm{T}$, any $\mathrm{N}, \mathrm{M} 1$ & Any T, any N, M1 \\
\hline
\end{tabular}

Adapted from the American Joint Committee on Cancer (AJCC) Cancer Staging Manual, 8th Edition

Table 2. Histologic Grade for Gastrointestinal of Neuroendocrine Tumors (European Neuroendocrine Tumor Society/ World Health Organization grading system, 2010)

\begin{tabular}{ccc}
\hline & Mitotic index (mitoses/HPF) & Ki-67 index (\%) \\
\hline GX & Grade cannot be assessed & \\
G1 & $<2$ & $<3$ \\
G2 & $2-20$ & $3-20$ \\
G3 & $>20$ & $>20$ \\
\hline
\end{tabular}

copy and endoscopic ultrasound (EUS) may be helpful in the diagnosis of NETs, while advanced endoscopic techniques such as endoscopic mucosal resection (EMR) and endoscopic submucosal dissection (ESD) may form the cornerstone of SBNET management. In this review, we aimed to highlight the role of endoscopic techniques in the diagnosis and management of SB-NETs.

HPF, high power field. 


\section{DUODENAL NEUROENDOCRINE TUMORS}

Duodenal NETs are frequently detected incidentally on upper GI endoscopy. Although they are most commonly nonfunctioning tumors (that is, no association with a clinical syndrome), duodenal NETs may also be associated with Zollinger-Ellison syndrome, with its clinical triad of reflux, peptic ulcer disease, and diarrhea. As the duodenum is within the reach of conventional endoscopy, its location allows for histological evaluation, assessment of tumor stage, and even curative endoscopic resection. ${ }^{8}$

\section{Endoscopic ultrasound}

The size and depth of invasion are important risk factors associated with lymph node and distant metastasis. ${ }^{9-13}$ Endoscopic ultrasound (EUS) offers a method for precise evaluation of the size and depth of invasion of duodenal NETs prior to resection, which is essential to determine the method of resection: endoscopic or surgical.

In lesions less than $10 \mathrm{~mm}$ in size, the risk of lymph node or distant metastasis and recurrence is low. ${ }^{10,14,15}$ If invasion of the muscularis propria is excluded on EUS, endoscopic resection is appropriate for tumors of this size. ${ }^{7,13,14,16}$ A duodenal NET greater than $20 \mathrm{~mm}$ in size is associated with a higher risk of recurrence and reduced disease-specific survival, ${ }^{11,13}$ and is an indication for surgical resection to obtain wider margins. For
NETs between 10 and $20 \mathrm{~mm}$, the data are less clear. In the absence of muscularis propria invasion on EUS, initial endoscopic resection may be considered. Surgical resection should be considered if high-risk features such as lymphovascular invasion, high grade, high mitotic index, or muscularis propria invasion, are found on pathologic examination.

\section{Endoscopic resection}

With the advantage of avoiding surgical morbidity, a trend towards endoscopic over surgical resection for duodenal NETs has been reported. ${ }^{17}$ NETs are submucosal lesions; thus, simple polypectomy is not considered effective. Various techniques have been described for resection; however, there is no consensus regarding the optimum technique. Endoscopic mucosal resection (EMR), endoscopic submucosal dissection (ESD), and variants of these techniques have been studied. The resection technique selected should have the greatest likelihood of en bloc resection and $\mathrm{R} 0$ resection (histologically clear lateral and deep margins). The rate of adverse events must also be considered, as the duodenum is thin-walled and has a higher risk of perforation than other areas of the GI tract (Table 3). Data on long-term outcomes and recurrence are limited due to short follow-up times in available studies.

EMR uses submucosal injection to lift and separate the lesion from the muscularis propria. This creates an elevated lesion that can be resected with snare cautery (Fig. 1). However, EMR can result in crush and coagulation injury to the margins

Table 3. Endoscopic Resection Techniques for Duodenal NET

\begin{tabular}{|c|c|c|c|}
\hline Technique & Patient selection & Advantages & Disadvantages \\
\hline EMR/ Band-EMR & $\begin{array}{l}\text { Lesions }<10 \mathrm{~mm} \text { without muscularis } \\
\text { propria invasion } \\
\text { Consider for lesions } 10-20 \mathrm{~mm} \text { with- } \\
\text { out muscularis propria invasion }\end{array}$ & $\begin{array}{l}\text { Simple technique, short procedure } \\
\text { time } \\
\text { Low risk of adverse events } \\
\text { Band-EMR may improve deep mar- } \\
\text { gin }\end{array}$ & $\begin{array}{l}\text { Can be difficult to achieve en-bloc and } \\
\text { R0 resection, especially for deep mar- } \\
\text { gin (improved with band-EMR) } \\
\text { Coagulation injury to specimen may } \\
\text { limit histologic assessment of margins }\end{array}$ \\
\hline ESD & $\begin{array}{l}\text { Lesions } \leq 20 \mathrm{~mm} \text { without muscularis } \\
\text { propria invasion } \\
\text { Consider for lesions }>20 \mathrm{~mm} \text { with- } \\
\text { out muscularis propria invasion }\end{array}$ & $\begin{array}{l}\text { Superior en-bloc and } \mathrm{R} 0 \text { resection } \\
\text { rates compared to EMR }\end{array}$ & $\begin{array}{l}\text { High adverse event rate in the duode- } \\
\text { num (perforation, delayed bleeding) } \\
\text { Long procedure time }\end{array}$ \\
\hline EFTR & $\begin{array}{l}\text { Lesions } \leq 20 \mathrm{~mm} \text { without muscularis } \\
\text { propria invasion } \\
\text { Consider for lesions } 10-20 \mathrm{~mm} \\
\text { without muscularis propria inva- } \\
\text { sion } \\
\text { May be considered as salvage pro- } \\
\text { cedure for recurrent/ residual NET } \\
\text { after EMR/ESD }\end{array}$ & $\begin{array}{l}\text { Can achieve full-thickness resection } \\
\text { High R0 resection rate }\end{array}$ & $\begin{array}{l}\text { High adverse event rate (perforation, } \\
\text { delayed bleeding) } \\
\text { Longer procedure time than EMR }\end{array}$ \\
\hline
\end{tabular}

EMR, endoscopic mucosal resection; ESD, endoscopic submucosal dissection; EFTR, endoscopic full-thickness resection; NET, neuroendocrine tumor. 


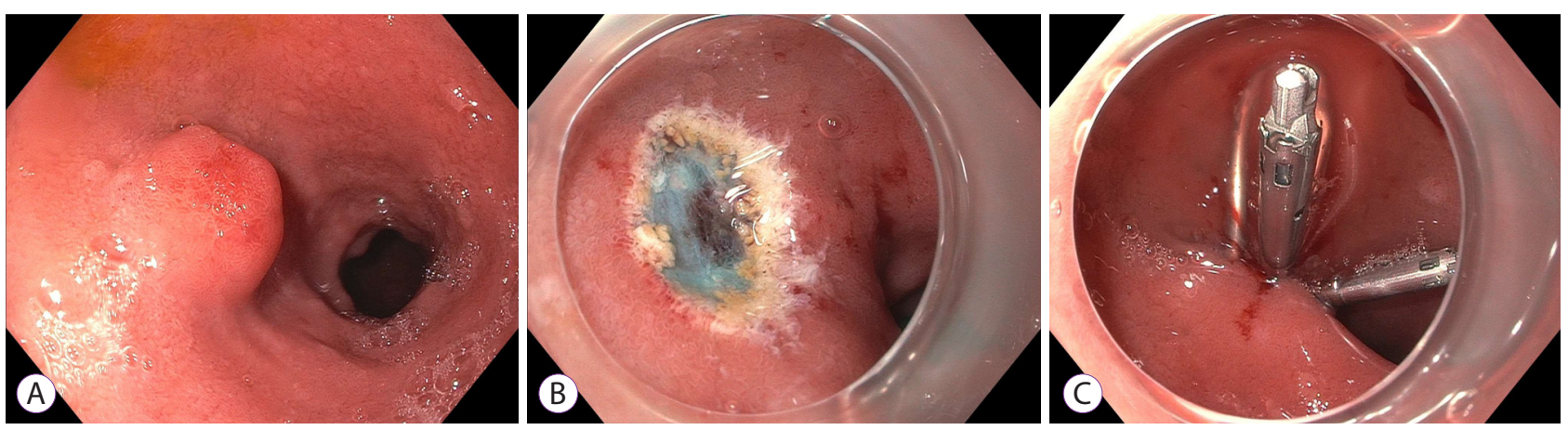

Fig. 1. Endoscopic mucosal resection of a duodenal neuroendocrine tumor. (A) A duodenal bulb neuroendocrine tumor. (B) After endoscopic mucosal resection. (C) Closure of mucosal defect using clips.

of the specimen, which can limit pathologic assessment. In addition, en bloc resection and a clear deep margin can be difficult to achieve, even with injection lifting of the lesion. Band ligation-assisted EMR (band-EMR or EMR-ligation; EMR-L) has been proposed as an alternative technique that avoids these drawbacks. In band-EMR, tissue is suctioned into a cap, and a band is deployed underneath, creating a pseudo-polyp. Snare cautery is used to resect underneath the band, which may create a deeper vertical margin.

In duodenal NETs, EMR achieves en bloc resection in 88$97 \%$ of cases and R0 resection in $63-97 \%$ of cases. ${ }^{18,19}$ Similarly, band-EMR achieves en bloc resection in 100\% of cases and R0 resection in $61-92 \%$ of cases. ${ }^{18-22}$ Notably, all vertical margins with band-EMR were found to be negative in one study. ${ }^{20}$ Reported complications are similar for both techniques, including intraprocedural bleeding, delayed bleeding, and perforation in $10-12 \%, 0-6 \%$, and $0-6 \%$ of cases, respectively. ${ }^{18-21}$ With an average of $15 \mathrm{~min}$, EMR has the advantage of a short procedure time. ${ }^{21}$

ESD has demonstrated superior en bloc and R0 resection rates in comparison to EMR: ${ }^{18}$ however, the duodenum is a technically challenging location with higher complication rates. ESD involves marking the border of the lesion before a circumferential mucosal incision is made using an electrosurgical knife. Submucosal dissection is then performed with the knife, as close to the muscularis propria as possible. The defect can then be closed using clips. ESD achieves en bloc resection in $80-100 \%$ of cases, and R0 resection in $88-100 \%$ of cases for the duodenum. ${ }^{23-26}$ Although these studies are limited by small numbers, there appears to be high rates of adverse events, with some studies reporting perforation in $23-25 \%$ of cases, and delayed bleeding in $7 \%$ of cases. ${ }^{23,24}$ The average procedure time is around $90 \mathrm{~min}^{23,27}$
Over-the-scope clip-assisted endoscopic full-thickness resection (EFTR) has also been proposed as a method to improve the deep resection margin. At first, the border of the lesion is marked using argon plasma coagulation or an electrosurgical knife. The lesion is then suctioned into the cap, sometimes using a tri-prong anchor to further retract the tissue into the cap. An over-the-scope clip is deployed over the retracted tissue, creating a pseudo-polyp. The tissue above the clip is then resected using an electrocautery snare. The deployment of the over-the-scope clip allows for deep resection with closure of the defect, theoretically minimizing the risk of perforation. Use of this technique in the duodenum has been limited, but studies to date have reported R0 resection in 100\% of cases. ${ }^{28-30}$ EFTR has also been successfully used as a salvage procedure for recurrent or residual NET after EMR or ESD. ${ }^{31}$ Reports of adverse events have been variable due to limited numbers in each study. In one study that included 6 duodenal NETs, perforation, micro-perforation, and hemorrhage occurred in $1 / 6,3 / 6$ and $1 / 6$ of cases, respectively. ${ }^{30}$ In two other studies with similar numbers, no adverse events were reported. ${ }^{28,29}$ The reported procedure time was approximately 50 $\min ^{28}$

\section{Jejunal and ileal neuroendocrine tumors}

Midgut NETs are classically associated with carcinoid syndrome and are often associated with significant symptoms, including gastrointestinal bleeding, abdominal pain, and diarrhea. Ileal NETs are much more common compared to jejunal NETs and are often associated with multifocal disease. Ileal NETs are sometimes found incidentally on intubation of the ileocecal valve during screening colonoscopy. Due to their less accessible location, jejunal and ileal NETs may present a diagnostic challenge. 


\section{Video capsule endoscopy}

The role of video capsule endoscopy (VCE) in diagnosis of SB-NETs is not yet clearly established, and guidelines defer to local expertise for its use. ${ }^{5,32}$ VCE may be useful in identifying multifocal NETs which may occur in $30-50 \%$ of patients and potentially confer a poorer prognosis than those with solitary tumors. ${ }^{33}$ Although the sensitivity of imaging and scintigraphy for detection of the primary small bowel tumor has increased in recent years, ${ }^{34}$ the sensitivity of imaging in the detection of multicentric carcinoid tumors has not been evaluated. In this context, use of VCE in preoperative evaluation may be considered to aid in determining the extent of resection.

The use of VCE may also be considered in patients with metastatic NETs of unknown origin before surgical exploration. Metastatic disease (usually in the liver) is found in $11 \%$ of patients with well-differentiated NETs, but the primary tumor remains unknown. ${ }^{35}$ On surgical exploration, the majority of metastatic NETs are found within the small bowel, and not detected on cross-sectional imaging or scintigraphy. ${ }^{36}$ The identification of the primary tumor is important, as some data have suggested that the resection of the primary tumor may improve prognosis even in metastatic disease..$^{37}$ In general, the diagnostic yield of VCE in the identification of small bowel tumors is low (2-9\%). ${ }^{38-41}$ In patients having NETs with unknown primary tumors, VCE had $75 \%$ sensitivity and $38 \%$ specificity compared to exploratory surgery. ${ }^{42}$

VCE can be limited by false positive mass lesions visualized due to contractions of the small bowel and extrinsic compression. When a true mass is seen, the endoscopic appearance is not definitive, and localization is inexact. A scoring system for endoscopic findings has been suggested to identify suspicious bulges requiring further investigation, ${ }^{43}$ but this has not been validated in a large cohort. Upon identification via VCE, a further invasive procedure such as balloon enteroscopy is required to confirm the findings and obtain pathological confirmation. Somatostatin receptor scintigraphy using ${ }^{68} \mathrm{Ga}$-DOTATATE has improved detection compared to previous agents. However, in its absence, VCE may still be of value given its low risk, especially before exploratory surgery.

\section{Balloon enteroscopy}

Since its introduction in the year 2004, balloon enteroscopy (BE) has extended the reach of endoscopic techniques to the previously inaccessible small bowel for various indications, ${ }^{44}$ including the evaluation of small bowel tumors. The diagnostic yield of $\mathrm{BE}$ for small bowel tumors across all indications has been estimated at 4-14\%. ${ }^{45-48}$ In patients with suspected NET but negative initial workup, the diagnostic yield is up to $33 \%{ }^{49}$ In one study, BE had $88 \%$ sensitivity for the primary
SB-NET compared to $60 \%$ for CT, $54 \%$ for MRI, and $56 \%$ for somatostatin receptor imaging. ${ }^{50}$

BE may also be considered to identify multifocal NETs prior to surgery. In one retrospective study of patients who had undergone small bowel resection, BE prior to surgery identified additional lesions in $54 \%$ of patients, compared to $18 \%$ undergoing VCE. ${ }^{51}$ In another study with a similar design, small bowel enteroscopy had only a 10\% yield, compared with VCE with a $83 \%$ yield. ${ }^{52}$ However, VCE only identified the correct number of tumors in $21 \%$ of these cases.

The use of BE may be limited because it is restricted to referral centers. Given these limitations, multifocal tumors may be most reliably found during surgery, by examining the entire bowel, as emphasized by NANETS guidelines. ${ }^{53}$ Although endoscopic interventions, including biopsy, clipping, and EMR (including resection of a carcinoma) have been shown to be feasible through $\mathrm{BE}$ with minimal complications, ${ }^{47}$ this practice is not widespread, and surgical resection remains the mainstay for jejunal and ileal NETs. Endoscopic resection of jejunal and ileal NETs is not recommended as even diminutive (sub-centimeter) small bowel lesions may be associated with invasion and lymphatic spread, requiring a more extensive surgical resection.

\section{CONCLUSIONS}

Endoscopy is the cornerstone of the diagnosis and management of SB-NETs. In the duodenum, EUS is an essential technique that allows assessment of tumor size and depth of invasion, which is necessary to select appropriate candidates for endoscopic resection. Multiple endoscopic techniques, including EMR, band-EMR, EFTR, and ESD have been studied for the resection of NETs in the duodenum. It can be difficult to achieve clear margins through EMR for NETs; however, there is currently no consensus on an optimal technique. In jejunal and ileal NETs, endoscopy is mainly for diagnosis, identifying multifocal tumors before surgical resection, or localizing the primary lesion in metastatic NETs where the initial workup is unrevealing.

Conflicts of Interest

The authors have no potential conflicts of interest.

Funding

None.

Author Contributions

Conceptualization: Ji Yoon Yoon, Michelle Kang Kim

Investigation: JYY 
Supervison: Nikhil A. Kumta, MKK

Writing-original draft: JYY

Writing-review\&editing: JYY, NAK, MKK

\section{ORCID}

Ji Yoon Yoon:

Nikhil A. Kumta:

Michelle Kang Kim:

https://orcid.org/0000-0002-8897-7144

https://orcid.org/0000-0002-8090-7846

https://orcid.org/0000-0001-5285-8218

\section{REFERENCES}

1. Dasari A, Shen C, Halperin D, et al. Trends in the incidence, prevalence, and survival outcomes in patients with neuroendocrine tumors in the United States. JAMA Oncol 2017;3:1335-1342.

2. Yao JC, Hassan M, Phan A, et al. One hundred years after "carcinoid": epidemiology of and prognostic factors for neuroendocrine tumors in 35,825 cases in the United States. J Clin Oncol Off J Am Soc Clin Oncol 2008;26:3063-3072.

3. Bilimoria KY, Bentrem DJ, Wayne JD, Ko CY, Bennett CL, Talamonti MS. Small bowel cancer in the United States: changes in epidemiology, treatment, and survival over the last 20 years. Ann Surg 2009;249:63-71.

4. Lawrence B, Gustafsson BI, Chan A, Svejda B, Kidd M, Modlin IM. The epidemiology of gastroenteropancreatic neuroendocrine tumors. Endocrinol Metab Clin North Am 2011;40:1-18.vii.

5. Boudreaux JP, Klimstra DS, Hassan MM, et al. The NANETS consensus guideline for the diagnosis and management of neuroendocrine tumors: well-differentiated neuroendocrine tumors of the Jejunum, Ileum, Appendix, and Cecum. Pancreas 2010;39:753-766.

6. Landerholm K, Falkmer S, Järhult J. Epidemiology of small bowel carcinoids in a defined population. World J Surg 2010;34:1500-1505.

7. Dalenbäck J, Havel G. Local endoscopic removal of duodenal carcinoid tumors. Endoscopy 2004;36:651-655.

8. Kulke MH, Shah MH, Benson AB, et al. Neuroendocrine tumors, version 1.2015. J Natl Compr Cancer Netw JNCCN 2015;13:78-108.

9. Burke AP, Sobin LH, Federspiel BH, Shekitka KM, Helwig EB. Carcinoid tumors of the duodenum. A clinicopathologic study of 99 cases. Arch Pathol Lab Med 1990;114:700-704.

10. Hatta W, Koike T, Iijima K, et al. The risk factors for metastasis in non-ampullary duodenal neuroendocrine tumors measuring $20 \mathrm{~mm}$ or less in diameter. Digestion 2017;95:201-209.

11. Zyromski NJ, Kendrick ML, Nagorney DM, et al. Duodenal carcinoid tumors: how aggressive should we be? J Gastrointest Surg Off J Soc Surg Aliment Tract 2001;5:588-593.

12. Untch BR, Bonner KP, Roggin KK, et al. Pathologic grade and tumor size are associated with recurrence-free survival in patients with duodenal neuroendocrine tumors. J Gastrointest Surg Off J Soc Surg Aliment Tract 2014;18:457-462; discussion 462-463.

13. Vanoli A, La Rosa S, Klersy C, et al. Four neuroendocrine tumor types and neuroendocrine carcinoma of the duodenum: analysis of 203 cases. Neuroendocrinology 2017;104:112-125.

14. Park SG, Lee BE, Kim GH, et al. Risk factors for lymph node metastasis in duodenal neuroendocrine tumors: A retrospective, single-center study. Medicine (Baltimore) 2019;98:e15885.

15. Lee SW, Sung JK, Cho YS, et al. Comparisons of therapeutic outcomes in patients with nonampullary duodenal neuroendocrine tumors (NADNETs): a multicenter retrospective study. Medicine (Baltimore) 2019;98:e16154.

16. Delle Fave G, O'Toole D, Sundin A, et al. ENETS consensus guidelines update for gastroduodenal neuroendocrine neoplasms. Neuroendocrinology 2016;103:119-124.

17. Kumar S, Mahmud N, Roses RE, Katona BW, Ginsberg GG, Metz DC. Resection trends for duodenal carcinoid tumors: a single-center experi- ence. Pancreas 2020;49:E11-E13.

18. Kim GH, Kim JI, Jeon SW, et al. Endoscopic resection for duodenal carcinoid tumors: a multicenter, retrospective study. J Gastroenterol Hepatol 2014;29:318-324.

19. Park SB, Kang DH, Choi CW, Kim HW, Kim SJ. Clinical outcomes of ligation-assisted endoscopic resection for duodenal neuroendocrine tumors. Medicine (Baltimore) 2018;97:e0533.

20. Fujimoto A, Sasaki M, Goto O, et al. Treatment results of endoscopic mucosal resection with a ligation device for duodenal neuroendocrine tumors. Intern Med Tokyo Jpn 2019;58:773-777.

21. Osera S, Oono Y, Ikematsu H, Yano T, Kaneko K. Endoscopic submucosal resection with a ligation device for the treatment of duodenal neuroendocrine tumors. Surg Endosc 2016;30:3928-3932.

22. Oono Y, Shinmura K, Hori K, et al. Endoscopic submucosal resection using a ligation device without injection for duodenal neuroendocrine tumors. Surg Endosc 2019;33:2008-2014.

23. Matsumoto S, Miyatani H, Yoshida Y. Endoscopic submucosal dissection for duodenal tumors: a single-center experience. Endoscopy 2013;45:136-137.

24. Nishio M, Hirasawa K, Ozeki Y, et al. Short- and long-term outcomes of endoscopic submucosal dissection for non-ampullary duodenal neuroendocrine tumors. Ann Gastroenterol 2020;33:265-271.

25. Kim SH, Park CH, Ki HS, et al. Endoscopic treatment of duodenal neuroendocrine tumors. Clin Endosc 2013;46:656-661.

26. Li Q-L, Zhang Y-Q, Chen W-F, et al. Endoscopic submucosal dissection for foregut neuroendocrine tumors: an initial study. World J Gastroenterol 2012;18:5799-5806.

27. Matsumoto S, Miyatani H, Yoshida Y, Nokubi M. Duodenal carcinoid tumors: 5 cases treated by endoscopic submucosal dissection. Gastrointest Endosc 2011;74:1152-1156.

28. Al-Bawardy B, Rajan E, Wong Kee Song LM. Over-the-scope clip-assisted endoscopic full-thickness resection of epithelial and subepithelial GI lesions. Gastrointest Endosc 2017;85:1087-1092.

29. Sarker S, Gutierrez JP, Council L, Brazelton JD, Kyanam Kabir Baig KR, Mönkemüller K. Over-the-scope clip-assisted method for resection of full-thickness submucosal lesions of the gastrointestinal tract. Endoscopy 2014;46:758-761.

30. Kappelle WFW, Backes Y, Valk GD, Moons LMG, Vleggaar FP. Endoscopic full-thickness resection of gastric and duodenal subepithelial lesions using a new, flat-based over-the-scope clip. Surg Endosc 2018;32:2839-2846.

31. Hajifathalian K, Ichkhanian Y, Dawod Q, et al. Full-thickness resection device (FTRD) for treatment of upper gastrointestinal tract lesions: the first international experience. Endosc Int Open 2020;8:E1291-E1301.

32. Niederle B, Pape U-F, Costa F, et al. ENETS consensus guidelines update for neuroendocrine neoplasms of the Jejunum and Ileum. Neuroendocrinology 2016;103:125-138.

33. Yantiss RK, Odze RD, Farraye FA, Rosenberg AE. Solitary versus multiple carcinoid tumors of the ileum: a clinical and pathologic review of 68 cases. Am J Surg Pathol 2003;27:811-817.

34. Koopmans KP, de Vries EGE, Kema IP, et al. Staging of carcinoid tumours with 18F-DOPA PET: a prospective, diagnostic accuracy study. Lancet Oncol 2006;7:728-734.

35. Bellizzi AM. Assigning site of origin in metastatic neuroendocrine neoplasms: a clinically significant application of diagnostic immunohistochemistry. Adv Anat Pathol 2013;20:285-314.

36. Wang SC, Parekh JR, Zuraek MB, et al. Identification of unknown primary tumors in patients with neuroendocrine liver metastases. Arch Surg Chic Ill 1960 2010;145:276-280.

37. Ahmed A, Turner G, King B, et al. Midgut neuroendocrine tumours with liver metastases: results of the UKINETS study. Endocr Relat Cancer 2009;16:885-894.

38. Rondonotti E, Pennazio M, Toth E, et al. Small-bowel neoplasms in patients undergoing video capsule endoscopy: a multicenter European 
study. Endoscopy 2008;40:488-495.

39. Cobrin GM, Pittman RH, Lewis BS. Increased diagnostic yield of small bowel tumors with capsule endoscopy. Cancer 2006;107:22-27.

40. Bailey AA, Debinski HS, Appleyard MN, et al. Diagnosis and outcome of small bowel tumors found by capsule endoscopy: a three-center Australian experience. Am J Gastroenterol 2006;101:2237-2243.

41. Lewis BS, Eisen GM, Friedman S. A pooled analysis to evaluate results of capsule endoscopy trials. Endoscopy 2005;37:960-965.

42. Furnari M, Buda A, Delconte G, et al. The role of wireless capsule endoscopy (WCE) in the detection of occult primary neuroendocrine tumors. J Gastrointest Liver Dis JGLD 2017;26:151-156.

43. Girelli CM, Porta P, Colombo E, Lesinigo E, Bernasconi G. Development of a novel index to discriminate bulge from mass on small-bowel capsule endoscopy. Gastrointest Endosc 2011;74:1067-1074; quiz 1115. e1-e5.

44. Yamamoto H, Kita H, Sunada K, et al. Clinical outcomes of double-balloon endoscopy for the diagnosis and treatment of small-intestinal diseases. Clin Gastroenterol Hepatol 2004;2:1010-1016.

45. Imaoka H, Higaki N, Kumagi T, et al. Characteristics of small bowel tumors detected by double balloon endoscopy. Dig Dis Sci 2011;56:23662371.

46. Partridge BJ, Tokar JL, Haluszka O, Heller SJ. Small bowel cancers diagnosed by device-assisted enteroscopy at a U.S. referral center: a five-year experience. Dig Dis Sci 2011;56:2701-2705.

47. Mitsui K, Tanaka S, Yamamoto H, et al. Role of double-balloon endoscopy in the diagnosis of small-bowel tumors: the first Japanese multicenter study. Gastrointest Endosc 2009;70:498-504.

48. Cangemi DJ, Patel MK, Gomez V, Cangemi JR, Stark ME, Lukens FJ. Small bowel tumors discovered during double-balloon enteroscopy: analysis of a large prospectively collected single-center database. J Clin Gastroenterol 2013;47:769-772.

49. Bellutti M, Fry LC, Schmitt J, et al. Detection of neuroendocrine tumors of the small bowel by double balloon enteroscopy. Dig Dis Sci 2009;54:1050-1058

50. Manguso N, Gangi A, Johnson J, et al. The role of pre-operative imaging and double balloon enteroscopy in the surgical management of small bowel neuroendocrine tumors: Is it necessary? J Surg Oncol 2018;117:207-212.

51. Gangi A, Siegel E, Barmparas G, et al. Multifocality in small bowel neuroendocrine tumors. J Gastrointest Surg 2018;22:303-309.

52. Ethun CG, Postlewait LM, Baptiste GG, et al. Small bowel neuroendocrine tumors: a critical analysis of diagnostic work-up and operative approach. J Surg Oncol 2016;114:671-676.

53. Howe JR, Cardona K, Fraker DL, et al. The surgical management of small bowel neuroendocrine tumors: Consensus guidelines of the North American Neuroendocrine Tumor Society. Pancreas 2017;46:715-731. 